Journal of Social Sciences 7 (3): 349-353, 2011

ISSN 1549-3652

(C) 2011 Science Publications

\title{
A Comparison of Small-Side Games and Interval Training on Same Selected Physical Fitness Factors in Amateur Soccer Players
}

\author{
${ }^{1}$ Ali Mohammad Safania, ${ }^{2}$ Rostam Alizadeh and ${ }^{3}$ Maryam Nourshahi \\ ${ }^{1}$ Department of Physical Education, Islamic Azad University, \\ Ayatollah Amoli Branch, Mazanderan \\ ${ }^{2}$ Ministry of Science Research and Technology Sport Sciences Research Center, \\ ${ }^{3}$ Department of Exercise Physiology Shahid Beheshti University GC, \\ Physical Education Faculty, Tehran, Iran
}

\begin{abstract}
Problem statement: Soccer is a team sport with an intermittent nature in which the athletes need to improve their physical fitness and skill factors in order to engage in high intensity exercises. The aim of this study was a comparison of small-side game and interval training on some selected physical fitness in amateur soccer players. Approach: Twenty, soccer players (height $165.34 \pm 4.75$ $\mathrm{cm}$, weight $58.5 \pm 5.22 \mathrm{~kg}$, age $15.7 \pm 0.7$ years), were randomly selected and assigned to two groups (intermittent training, specific training in form of Small-Side Game (SSG)) 3 times a week for 6 weeks. The intensity of two training programs was similar according to heart rate (70-95\% HR max, progressively and time (4 bouts of $4 \mathrm{~min}$ at $70 \%-95 \%$ of maximum heart rate with 3 min active rest periods). For measuring the above variables 12-min running test and RAST test were used, respectively. Data analysis by independent and dependent $\mathrm{T}$ test, the level of significance in all statistical analyses was set at $p \leq 0.05$. Results: Results showed that the 6-week training of both groups significantly increased in all the variables, $\left(\mathrm{Vo}_{2} \max\right.$, maximum power, minimum power, average power and RSA variable). Conclusion: according to the results of the study, it is recommended to employ specific training in preparatory programs (especially, of in-season), because such training, in a similar amount of time improve the same physical fitness factors of amateur soccer players and they are applicable in soccer players.
\end{abstract}

Key words: Interval training, detrimental index, small-side game, soccer players, training methods

\section{INTRODUCTION}

Soccer is one of the most exponent sports in most societies all people in society whether woman, man, old man, young and children are interested in soccer. The first reason for this generalization is that it doesn't require much equipment. In order to improve soccer performance in sport teams, technique, tactics and physical fitness are often of special importance (Stolen et al., 2005). Physical fitness play an important role in a soccer game, so that a player has to make a decision at any time is good for that special occasion. When the athlete is tired, his activity becomes slow and discordant and consequently his technique will be influenced.Elite professional players run about $10 \mathrm{kms}$ (on the average at $80-90 \%$ of heart rate) at their anaerobic threshold. A soccer player needs several explosive burst activities such as jumping, kicking, tackling, Turing, sprinting, changing position area and making strong contraction to keep balance and control the ball against the competitor presses (Stolen et al., 2005).

While teams have same tactics and skill abilities, a team with higher general fitness is superior team and act more powerful when the game gains speed (Science and Soccer, 2003).One of the commend training methods in soccer is employing interval training. Regard to the intervals of training period and rest in interval training is necessary. Interval training can also increase the speed or the ability of keeping speed in long term periods in addition to improvement of aerobic ability resulting from the rest periods between the activities. Helgerud, et al. (2001) showed that $\mathrm{Vo}_{2} \max$, lactate threshold and running economy improved by 11 , 16 and $7 \%$ respectively after the interval training two times a week for 8 weeks (4 bouts of 4 min at 90-95\% of maximum heart rate with 3 min active rest periods).

Corresponding Author: Ali Mohammad Safania, Department of Physical Education, Islamic Azad University, Ayatollah Amoli Branch, Mazanderan 


\section{J. Social Sci., 7 (3): 349-353, 2011}

Furthermore, total distance covered increased by $20 \%$, average intense during a match increased by $25 \%$ and the number of sprint doubled and involvements with the ball during a match increased by $23 \%$ (Helgerud et al., 2001).

But many former instructors traditionally still use long term running at $70 \%-80 \%$ of maximum heart rate.Using training methods may be difficult for athletes which have to use several sprints with short distance during a match. The researches show that using long term running can reduce anaerobic capacity and the activity of glicolitic enzymes. Since every few years, the rules and regulations of games especially soccer (like the rule of passing back 1992 and 6s goal keeper, 1997 (Dupont et al., 2004) all the changes were made to speed up play during a match and that the ball be in the course more time. So because the athlete can keep the intensity of game during $90 \mathrm{~min}$ and show the best response during man to man contacts, counter attacks, sending high passes and changing position area, physical fitness factors must be separately regarded in preparatory programs.

In contrast many researchers believe that soccer specific trainings like the small-side games training improve $\mathrm{Vo}_{2}$ max more than other trainings (Bangsbo, 1998; Drust et al., 2000; Reilly and Gilbourne, 2003). Moreover they recommend performance of a series of simulated trainings than intermittent trainings and believe that this trainings increase aerobic fitness and better performance in exercise (Hoff et al., 2002). Furthermore, it is recommended that ever the manner of arranging players in time training in small-side games must based on the kind of muscular groups involvement during a match and a soccer play (Bangsbo, 1998).The technique and tactics skills must be planned similar to actual condition and the athlete has a suitable performance when being under match condition (Reilly and Gilbourne, 2003). Haff, et al. reported that soccer players with higher $\mathrm{Vo}_{2} \max$ tend to show a lower $\mathrm{Vo}_{2} \max$ in time of trainings and small-side games and this problem was usually associated with teams in which the training program of most athletes was similar (Hoff et al., 2002).Then using this trainings like small-side games would not lead to enough stimulate for the physiologic adaption in all members.

As come from above studies, contradictory results has been given about different kindly of training and effectiveness of each one. Furthermore, few articles have referred both aerobic and anaerobic factors together. Regarding the importance of preparatory programs and the fact that soccer needs players with high $\mathrm{Vo}_{2}$ max and high explosive speed and low fatigue index, planning a program that would cause a suitable adaption with the simulation of match condition. Since players coaches commonly use the interval and smallside games training programs, but not a regular study has been made to review the effect of this training on physical fitness factors especially in our country. Therefore this study is going to answer this question that which method of training, interval or small-side games has more effect on improvement of the athletes' aerobic, agility and anaerobic systems.

\section{MATERIALS AND METHODS}

In this study after informing the soccer players twenty (height $165.34 \pm 4.75 \mathrm{~cm}$, weight $58.5 \pm 5.22 \mathrm{~kg}$, age $15.7 \pm 0.7$ years), having necessary condition including non-participating in other physical programs during the program and having physical health were selected and assigned to two equal groups intermittent training $(n=10)$, specific training in form of small-side game $(n=10)$ after taking the consent and filling the questioner. In an explanatory session, doing intense physical activity two days before the performance of test has not been let and non-participating in other physical programs during the program was emphasized. The pre-test was made in two process at an interval of 3 days consists of RAST test to evaluate anaerobic capacity in the first day and Kouper 12-min running test to evaluate $\mathrm{Vo}_{2} \max$ in the second day. Then both groups performed their special trainings three times a week for 6 weeks. Duration of each exercise was 80 min for both groups. Activity intensity for both groups was $70-95 \%$ of maximum heart rate, significantly increased by $5 \%$ every week which controlled by the coach during the exercise. The post-test was made like the pre-test after the end of the period.

Interval training group program: The subjects performed below interval trainings after 10 Min warmup: 4 bouts of 4 min with 3 min rest between each bout (Helgerud et al., 2001), (70\%-95\% HRmax, every week, increased 5\% HRmax to activity intensity) controlled by the coach. Then $5 \mathrm{~min}$ rest, $30 \mathrm{~min}$ competitive play and finally after $10 \mathrm{~min}$ recovery the exercise ended.

The small-side games group program: It contained technical and tactical small-side games trainings. They performed following activities simultaneously after 10min warm-up and rested 3 min between each activity, then 5 min rest and 30 min competitive play and finally exercises ended after 10 min recovery: 
- Three with 1 ball in a triangular area of $4 \mathrm{~m}$ (Bangsbo, 2007)

- 2-people two teams competed in a area with $10-15 \mathrm{~m}$ and empty goal doing their best (Bangsbo, 2007)

- 3-people two teams competed in a area with $35 \mathrm{~m} .35 \mathrm{~m}$ and empty goal with 2 balls doing their best (Impellizzeri et al., 2006)

- 4-people two teams competed in a area with 40$50 \mathrm{~m}$, empty goal with 2 balls doing their best (Impellizzeri et al., 2006)

Tests used in the research: $\mathrm{Vo}_{2} \max$ : 12-minute running test was used to measure $\mathrm{Vo}_{2}$ max. The obtained distance within $12 \mathrm{~min}$ was set in formula (1) and the subject $\mathrm{Vo}_{2} \max$ was computed:

$$
\text { Formula(1) } \mathrm{Vo}_{2_{\max }}=\frac{\text { Dis tan ce coverd }(\mathrm{m})-504.9}{44.73}
$$

Anaerobic capacity: (RAST) test was used to measure anaerobic capacity.

RAST test performance method: The weight of testable was measured and recorded before the test. The test consists of 6 maximal sprint repetitions of $35 \mathrm{~m}$ with 10 -second rest period between. Prior to conducting the test, the subjects performed light stretching for 10 min as warm-up. For obtaining desirable results from the RSA test, the subjects were asked to avoid distributing energy between the repetitions and to do their best for each exercise. For increasing the subjects' motivation, the recorded time of each repetition was reported to them. For each subject the fastest sprint time (the fastest $35 \mathrm{~m}$ running time among 6 repetitions) and the total sprint time (the total time of 6 repetitions of 35 $\mathrm{m}$ running) were recorded. Based on these data and using the following equation RSA was calculated (Dupont et al., 2005).

$$
\text { RAS } *=\frac{\begin{array}{l}
\text { fastest sprint time } \times \text { the } \\
\text { number of repetitions }
\end{array}}{\text { Total sprint time accumulated }} \times 100
$$

Statistical analysis: The average value and the standard deviation were used as central and scattering determinant respectively to describe studied variables and also to evaluate the normalization of numerical variables; Kulmogrov-Smirnov statistical test was used. Finally, spss 15 at $\mathrm{p}<0.05$ was applied to test resulting data. The couple $t$ test was used to determine the intergroup significance difference in different steps (pre-test-post-test) and the single $\mathrm{t}$ test was used for comparing the two groups( Table 1).

\section{RESULTS}

Results showed that 6-week training of both groups significantly increased in $\mathrm{Vo}_{2} \max$, maximum power, minimum power, average power and decremental index variable ( Table 2). Furthermore a comparison of the two groups showed there is no significant difference between $\mathrm{Vo}_{2} \max (\mathrm{p}=0.11, \mathrm{t}=1.6)$, maximum power $(\mathrm{p}=0.21, \mathrm{t}$ $=1.3)$, minimum power $(\mathrm{p}=0.89, \mathrm{t}=1.3)$, average power $(\mathrm{p}=0.56, \mathrm{t}=0.58)$ and decremental index $(\mathrm{p}=$ $0.36, \mathrm{t}=0.92)$.

\section{DISCUSSION}

Results showed that all variables increased in 6-week training than pre-test. In order to achieve optimal fitness and making effective adaption, all systems should being under overload and under press. To attain this purpose, player coaches and athletes use systematically a set of training principle including overload principle, training characteristic principle and so on called training timing (Bompa et al., 2004). Metabolic, cardiovascular and neuromuscular coordination can be generated through relatively intense regular trainings which depend on the duration and intense rate. Since the subjects were amateur soccer players which had no exercise or being at very low level of activity for their final exams, above mentioned factors improvement seems obvious.

\begin{tabular}{|c|c|c|c|c|}
\hline \multirow{2}{*}{$\begin{array}{l}\text { Groups } \\
\text { Determinants }\end{array}$} & \multicolumn{2}{|c|}{ Interval training } & \multicolumn{2}{|l|}{ SSG training } \\
\hline & Post-test & Pre-test & Post-test & Pre-test \\
\hline $\mathrm{Vo}_{2 \max }\left(\mathrm{ml} \mathrm{kg}^{-1} \min ^{-1}\right)$ & $43.48 \pm 1.38$ & $33.96 \pm 1.38$ & $42.89 \pm 1.42$ & $34.19 \pm 1.6$ \\
\hline Maximum power (w) & $362 \pm 25$ & $287.5 \pm 39$ & $348 \pm 46$ & $265.5 \pm 27$ \\
\hline Minimum power (w) & $263 \pm 32$ & $177 \pm 36$ & $240 \pm 40$ & $150 \pm 23$ \\
\hline Average power (w) & $309 \pm 39$ & $220 \pm 24$ & $291 \pm 38$ & $207 \pm 29$ \\
\hline Decremental index (\%) & 0.945 & 0.898 & 0.938 & 0.900 \\
\hline
\end{tabular}
Comparing the two groups, results are as follows.

Table 1: The average and deviation standard of measured variables in pre-test and post-test 
Table 2: Results of analysis

\begin{tabular}{llll}
\hline Variable & $\mathrm{T}$ & $\mathrm{P}$ & Freedom degree \\
\hline $\mathrm{Vo}_{2 \max }$ & 1.60 & 0.110 & 18 \\
Maximum power & 1.30 & 0.210 & 18 \\
Minimum power & 1.30 & 0.890 & 18 \\
Average power & 0.58 & 0.560 & 18 \\
Decremental index & 0.92 & 0.360 & 18 \\
\hline
\end{tabular}

Results showed that $\mathrm{Vo}_{2} \max$ increased significantly in the interval and small-side game training groups during 6 weeks. But not statistically significant difference between the two groups was found. These findings are in agreement with the results obtained in Impellizzeri et al., 2006; Rampinin et al., 2007; Sassi et al., 2003; Stephan et al., 2009). Although not statistically significant difference between $\mathrm{Vo}_{2 \max }$ was found, however difference between the averages $(8.69 \pm 1.34$ in small-side games training) and (9.52 \pm 0.84 in interval training) shows that $\mathrm{Vo}_{2}$ max has increased more in the interval group. Though it's not significant level at $\mathrm{p}<0.05$. But it remembers the fact reported by Hoff et al. (2002) that players with higher $\mathrm{Vo}_{2} \max$ tend to show a lower $\mathrm{Vo}_{2}$ max in time of small-side games trainings and player coaches have to change playing area and number of players in each playing field and encourage players to avoid this problem in time of smallside game trainings (Rampinin et al., 2007).

Results showed that 6 weeks interval and smallside games training caused a significant increase in maximum power, minimum power and anaerobic capacity and detrimental index. Not similar research concerning maximum power, minimum power and anaerobic ability and detrimental index was found in time of training in small-side games. This result was similar to the results obtained Billat et al. (1999); Collins et al. (2000); Rozenenek et al. (2000); Sokmen et al. (2002). Though aerobic metabolism is dominant system of energy in soccer play, but during a match, repeated short term interval activities are performed which such activities energy is supplied by phosphate system and lactic acid. Moreover according to made researches during a soccer match, the entire duration activity with high intensity is about $7 \mathrm{~min}$ for welltrained man players performed through 19sprint with time average of 2-3s (Stolen et al., 2005).Therefore the anaerobic system can be involved more times through interval training along with soccer play. Anaerobic capacity is influenced by several factors including genetics, age, gender, training, ATP and the way of muscular fibril distribution which difference in each of them can change anaerobic capacity (Bishop and Spencer, 2004; Seiler and Sjursen, 2002).

\section{CONCLUSION}

Young players need to develop and improve physiologic abilities affecting physical fitness and to generalize and adapt them with the soccer skills during a match. This physiological factors depend not only on the intensity of play but also on the direct involvement in activities with the ball. Since small-side games training causes more involvement with the ball and more opportunity to perform skills like passing, kicking, dribbling for the players, it can improve and develop physiologic abilities affecting physical fitness and adapt them with soccer skills during a match and the problem that small-side games training would not lead to enough stimulate for physiologic adaption of all members can be remove by changing the playing area, encouraging players and changing number of players in each playground section. As a result, since small-side games training in a similar amount of time has resulted in more increase of some of the selected physical fitness factors in this study, it is recommended that teams should apply specific training in preparatory programs especially in-season.

\section{ACKNOWLEDGEMENT}

This research was supported by a grant from Islamic Azad University, Ayatollah Amoli Branch. The authors wish to thank volunteers for their participation in the study.

\section{REFERENCES}

Bangsbo, J., 1998. Optimal preparation for the world cup in soccer. Clin. Sport Med., 17: 697-709. DOI: 10.1016/S0278-5919(05)70112-5

Bangsbo, J., 2007. Aerobic and Anaerobic Training in Soccer. 1st Edn., Institute of Exercise and Sport Sciences, Copenhagen.

Billat, V.L., B. Flechet, B. Petit, G. Muriaux and J.P. Koralsztein, 1999. Interval training at V[spacing dot above]O2max: Effects on aerobic performance and overtraining markers. Med. Sci. Sports Exerc., 31: 156-163. DOI: 10.1097/00005768-19990100000024

Bishop, D. and M. Spencer, 2004. Determinants of repeated-sprint ability in well-trained team-sport athletes and endurance-trained athletes. J. Sports Med. Phys. Fitness, 44: 1-7. PMid:15181383

Bompa, T.O. and G. Haff, 2004. Periodization. 5th Edn., Human Kinetics, Leeds, ISBN: 0736085475 , pp: 411. 
Drust, B., T. Reilly and N.T. Cable, 2000. Physiological Responses to Laboratory-Based Soccer-Specific Intermittent and Continuous Exercise. J. Sport Sci., 18 : 885-892. DOI: 10.1080/026404100750017814 PMid:11144865

Dupont, G., G.P. Millet, C. Guinhouya and S. Berthoin, 2005. Relationship between Oxygen Uptake Kinetics and Performance in Repeated Running Sprints. Eur. J. Appl. Physiol., 95: 27-34. DOI: $\quad 10.1007 /$ S00421-005-1382-8 PMid: $15976999 \mathrm{c}$

Dupont, G., K. Akakpo and S. Berthoin, 2004. The effect of in-season, high-intensity interval training in soccer players. J. Strength Cond. Res., 18: 584589. DOI: 10.1519/00124278-200408000-00034 PMid: 15320689

Helgerud, J., L.C. Engen, U. Wisloff and J. Hoff, 2001. Aerobic endurance training improves soccer performance. Med. Sci. Sports Exerc., 33: 19251931. DOI: 10.1097/00005768-200111000-00019 PMid: 11689745

Hoff, J., U. Wislff, L.C. Engen, O.J. Kemi and J. Helgerud, 2002.Soccer specific aerobic endurance training. Br. J. Sport Med., 36: 218-221. DOI: 10.1136/bjsm.36.3.218 PMid: 12055120 PMCid:1724499
Impellizzeri, F.M., S.M. Marcora, C. Castagna, T. Reilly and A. Sassi, et al., 2006. Physiological and performance effects of generic versus specific aerobic training in soccer players. Int. J. Sports Med., 27: 483-92. DOI: 10.1055/S-2005-865839 PMid: 167676

Rampinin, E., F.M. Impellizzeri, C. Castagna, G. Abt and K. Chamari, et al., 2007. Factors influencing physiological responses to small-sided soccer games. J. Sports Sci., 25: 659-66. DOI: 10.1080/02640410600811858 PMid: 17454533

Reilly, T. and G. Gilbourne, 2003. Science and football: A review of applied research in the football codes. J. Sport Sci., 21 :693-705. PMID: 14579867

Seiler, K.S. and J.E. Sjursen, 2002. Effect of work bout duration on physiological and perceptual responses to interval training in runners. Med. Sci. Sport Exer., 34: S274- S274. DOI: 10.1097/00005768200205001-01535

Sokmen, B., W. Beam, R. Witchey and G.F. Adams, 2002. Effect effect of interval versus continuous training on aerobic and anaerobic variables. Med. Sci. Sport Exerc., 34: 91-91. http://journals.lww.com/acsmmsse/Citation/2002/05001/Effect_of_Interval_Vers us_Continuous_Training_on.509.aspx

Stolen, T., K. Chamari, C. Castagna and U. Wislff, 2005. Physiology of soccer: An update. Sports Med., 35: 501-536. PMid: 15974635 